\title{
Pengaruh Penggunaan Metode Drill Terhadap Kemampuan Menggali Informasi Dari Dongeng Peserta Didik Kelas II Sekolah Dasar
}

\author{
Septia Wulandari ${ }^{1}$ \\ ${ }^{1}$ SDN 122/IX Petaling, Jambi, Indonesia
}

\begin{tabular}{l} 
Info Artikel \\
\hline Riwayat Artikel: \\
Received Jan 3, 2020 \\
Revised Jan 12, 2020 \\
Accepted Jan 25, 2020 \\
\hline
\end{tabular}

\section{Kata Kunci:}

Metode Drill

Sekolah Dasar

Menggali Informasi

Dongeng

\begin{abstract}
ABSTRAK
Tujuan Penelitian: Penelitian ini bertujuan untuk mengetahui pengaruh penggunaan metode drill terhadap kemampuan menggali informasi dari dongeng (fabel) tentang sikap hidup rukun dari teks lisan dan tulis peserta didik kelas II Sekolah Dasar Negeri 13/1 Muara Bulian.
\end{abstract}

Metodologi: Penelitian ini menggunakan pendekatan kuantitatif yang berbentuk quasi eksperimen. Subjek penelitian ini kelas IIC yang terdiri dari 23 siswa sebagai kelas kontrol dan IID yang terdiri dari 25 siswa sebagai kelas eksperimen.

Temuan Utama: Hasil penelitian menunjukan bahwa nilai rata-rata kelas eksperimen yaitu 88,2. Sedangkan nilai rata-rata kelas kontrol yaitu 62,86. Berdasarkan hasil uji hipotesis nilai post-test didapatkan $t_{\text {hitung }}>t_{\text {tabel }}$ $(0,1362<2,01290)$ yang dibuktikan dengan taraf signifikan $\alpha=0,05$ dan $\mathrm{dk}=46$ ini berarti hipotesis $\mathrm{H}_{\mathrm{a}}$ diterima dan $\mathrm{H}_{\mathrm{o}}$ ditolak, dengan demikian dapat disimpulkan bahwa penggunaan metode drill berpengaruh terhadap kemampuan menggali informasi dari dongeng peserta didik di kelas II Sekolah Dasar.

Corresponding Author:

Septia Wulandari

SDN 122/IX Petaling

Email: septia@gmail.com

\section{PENDAHULUAN}

Pembelajaran bahasa Indonesia di sekolah dasar bertujuan untuk meningkatkan keterampilan dan kemampuan siswa berkomunikasi dalam bahasa Indonesia yang baik dan benar, baik secara lisan maupun tulisan. Pembelajaran bahasa Indonesia dapat dilakukan dengan memadukan empat keterampilan berbahasa yaitu, membaca, menulis, berbicara dan menyimak. In language learning, there are four skills: listening, speaking, reading, and writing [1]. Empat keterampilan berbahasa tersebut sangat berkaitan erat dalam kemampuan berbahasa yang baik bagi peserta didik. Menurut Ref [2] membaca merupakan keterampilan dasar yang harus dimiliki setiap manusia yang menjadi sarana, untuk menangkap informasi, memperoleh informasi, ilmu, pengetahuan, dan pengalaman baru yang ada di tulisan. Pendapat tersebut menjelaskan bahwa dengan membaca dapat menangkap informasi, ilmu, pengetahuan melalui tulisan Ref [3]. Dalam kompetensi dasar kurikulum 2013 menyebutkan siswa kelas II sekolah dasar tidak hanya mampu membaca, namun juga harus mampu menggali informasi dari teks dongeng dan juga pengembangan sikap yang dapat diteladani dari teks dongeng lisan dan tulisan.

Ref [4] tentang standar isi pendidikan dasar dan menengah. Standar isi dikembangkan untuk menentukan kriteria ruang lingkup dan tingkat kompetensi yang sesuai dengan kompetensi lulusan yang dirumuskan pada standar kompetensi lulusan, yakni sikap, pengetahuan dan keterampilan. Pernyataan ini menjelaskan bahwa kriteria lulusan peserta didik harus memiliki sikap sosial maupun spiritual yang baik. Menurut Ref [5], proses pembelajaran menggali informasi dongeng teks lisan dan tulisan, terdapat banyak informasi, selain menghibur, juga terdapat ajaran tentang moral, amanat, pesan, nasihat dan bisa meneladani 
watak yang baik dari dongeng. Menurut Ref [6], exploring information from fairy tales of oral and written texts is an attempt to obtain good example in the formation and development of student attitudes. Berdasarkan hasil observasi awal yang dilakukan di kelas II sekolah dasar diperoleh informasi bahwa kemampuan peserta didik dalam menggali informasi dari teks lisan maupun tulisan masih belum optimal. Dalam kompetensi dasar kurikulum 2013 menyebutkan siswa kelas II sekolah dasar tidak hanya mampu membaca, namun juga harus mampu menggali informasi dari teks dongeng dan juga mampu mengembangan sikap yang dapat diteladani dari teks dongeng lisan dan tulisan. Salah satu cara yang dapat dilakukan dalam mencapai kompetensi peserta didik agar mampu menggali informasi dari dongeng tentang sikap hidup rukun dari teks lisan dan tulis adalah pemilihan metode pembelajaran. Salah satu metode yang sesuai dengan karakteristik peserta didik kelas II adalah metode Drill.

Menurut Ref [7], metode adalah rencana keseluruhan proses pembelajaran dari tahap penentuan tujuan pembelajaran, peran guru, peran siswa, materi, sampai tahap evaluasi pembelajaran. Metode drill adalah suatu kegiatan melakukan hal yang sama, berulang-ulang secara sungguh-sungguh dengan tujuan untuk memperkuat suatu asosiasi atau menyempurnakan suatu keterampilan agar menjadi sifat permanen. Menurut Ref [8], metode drill atau latihan merupakan suatu cara mengajar yang baik untuk menanamkan kebiasaan-kebiasaan tertentu utuk memperoleh kebiasaan-kebiasaan yang baik yang digunakan untuk memperoleh suatau ketangkasan, ketepatan, kesempatan, dan keterampilan dari apa yang telah dipelajari. Ciri khas dari metode drill adalah kegiatan berupa pengulangan yang berkali-kali dari suatu hal yang sama, dengan demikian terbentuklah pengetahuan-siap atau keterampilan-siap yang setiap saat siap untuk dipergunakan. Hal ini senada dengan pendapat Ref [9], bahwa aktivitas yang dilakukan dengan penuh ketekunan dalam rangka membangun pola komunikasi dengan diri sendiri untuk menemukan makna tulisan dan menemukan informasi untuk mengembangkan intlektualitas yang dilakukan dengan penuh kesadaran dan perasaan senang yang timbul dari dalam dirinya. Untuk itu, peneliti memilih metode yang sesuai dengan karakteristik usia sekolah dasar tersebut dan berlandaskan teori yang telah di paparkan tentang kemampuan menggali informasi dari dongeng peserta didik kelas II sekolah dasar yaitu metode drill. Metode tersebut dipilih berdasarkan karakteristik usia sekolah dasar kelas II sekolah dasar. Karakteristik peserta didik usia kelas II sekolah dasar merupakan usia pada tahapan perkembangan tahap operasional kongkrit yang berusia (7-11 tahun), pada tahap ini peserta didik membentuk sikap tertentu terhadap diri sendiri sebagai organisme yang sedang tumbuh, Membina keterampilan dasar dalam membaca, menulis dan berhitung, dan kegemaran dalam mengulang bermacam-macam kegiatan.

\section{METODE PENELITIAN}

Berdasarkan permasalahan yang diteliti yaitu "Pengaruh penggunaan metode drill terhadap kemampuan menggali informasi dari dongeng peserta didik di kelas II sekolah dasar, maka jenis data pada penelitian ini adalah kuantitatif dengan metode eksperimen dalam bentuk quasi experimental (eksperimen semu). Menurut Ref [10], metode eksperimen adalah metode penelitian yang digunakan untuk mencari pengaruh perlakuan tertentu terhadap yang lain dalam kondisi yang terkendalikan. Menurut Ref [10], quasi experimental mempunyai kelompok kontrol tetapi tidak dapat berfungsi sepenuhnya untuk mengontrol variabel-variabel luar yang mempengaruhi pelaksanaan eksperimen.

Penelitian ini menggunakan desain Non Equivalent Control Group Design. Terdapat dua kelompok yang dipilih berdasarkan karakteristik kelas yang sudah ada kemudian diberi pretest untuk mengetahui keadaan awal adakah perbedaan antara kelompok eksperimen dan kelompok kontrol. Hasil pre-test yang baik bila nilai kelompok eksperimen tidak berbeda secara signifikan. Dalam penelitian ini peneliti berusaha melihat dan mengungkapkan sejauh mana Pengaruh Metode drill terhadap kemampuan menggali informasi dari dongeng (fabel) dengan membandingkan hasil belajar kelas eksperimen dengan kelas kontrol. Kelas eksperimen diberi perlakuan (X) dengan penggunaan metode drill sedangkan kelas kontrol tidak diberikan perlakuan atau tidak menggunakan metode drill, selanjutnya kedua kelas diberikan posttest. Desain penelitian the nonequivalent control group design menurut Ref [10] yaitu pada tabel 1:

Tabel 1. Desain penelitian

\begin{tabular}{cccc}
\hline Kelas & Pre-test & Perlakuan & Post-test \\
\hline Eksperimen & $\mathrm{O}_{1}$ & $\mathrm{X}$ & $\mathrm{O}_{3}$ \\
Kontrol & $\mathrm{O}_{2}$ & - & $\mathrm{O}_{4}$ \\
\hline
\end{tabular}

Subjek pada penelitian ini yaitu peserta didik kelas II C yang berjumlah 23 peserta didik dan kelas II D yang berjumlah 25 peserta didik, di bagi menjadi kelas kontrol dan kelas eksperimen. Pemilihan karakteristik pada subjek penelitian ini berdasarkan jenis penelitian yang dipilih yaitu the non equivalent control group desain yaitu dengan memilih kelompok-kelompok yang sama keadaanya atau kondisinya.

JBER. Vol. 1, No. 1, Januari 2020: 1 - 6 
Rancangan eksperimen jenis ini menggunaan kelas-kelas yang sudah ada sebagai kelompok kontrol dan kelompok eksperimen.

Instrumen penelitian adalah alat atau fasilitas yang dipergunakan oleh peneliti dalam mengumulkan data agar hasilnya lebih baik, dalam arti lebih cermat, lengkap, dan sistematis sehingga lebih mudah untuk diolah. Ref [11] mengemukakan bahwa instrumen penelitian merupakan salah satu komponen penting yang diperlukan dalam penelitian. Jadi, instrumen penelitian diartikan sebagai alat yang digunakan peneliti untuk memperoleh serta mengolah informasi dari subjek penelitian. Pembuatan instrumen peneltian dilakukan dengan mengetahui secara jelas apa yang hendak diteliti, menentukan indikator yang hendak dijabarkan, dan butir-butir pertanyaan. Instrumen yang digunakan dalam penelitian ini berupa wawancara, tes dan observasi.

\section{HASIL DAN PEMBAHASAN}

Berdasarkan rumusan masalah dan tujuan penelitian maka dilakukan pengumpulan data tentang Pengaruh penggunaan metode drill terhadap kemampuan menggali informasi dari dongeng peserta didik kelas II di sekolah dasar. Penelitian ini dilakukan disekolah dasar dengan dua subjek penelitian yaitu kelas 2C sebagai kelas kontrol yang terdiri dari 23 peserta didik dan kelas 2D sebagai kelas eksperimen yang berjumlah 25 peserta didik.

Sebelum penelitian dilaksanakan, terlebih dahulu peneliti melakukan pengujian instrumen. Uji instrumen dilakukan untuk mengetahui apakah instrumen tersebut valid atau tidak untuk digunakan seperti yang dijelaskan oleh Ref [12-13]. Dalam hal ini peneliti mengujikan 4 instrumen soal. Untuk mengetahui valid atau tidak instrumen yang akan diujikan, maka setelah pengujian instrumen terhadap peserta didik, maka selanjutnya dilakukan uji validitas terhadap instrumen tersebut [14-15]. Uji validitas digunakan untuk mengukur tingkat kevalidan suatu instrumen, sebuah instrumen dikatakan valid apabila mampu mengukur apa yang ingin diukur secara teliti dan tepat [16]. Uji validitas pada penelitian ini berguna untuk mengujikan soal yang akan diujikan dan mencari soal yang valid [17], maka dari itu soal diujicobakan ke peserta didik untuk mengetahui soal tersebut valid atau tidaknya. Setelah dicobakan ke peserta didik barulah soal-soal tersebut di uji validitasnya. Dari uji validitas yang telah dilakukan, 4 soal yang diuji cobakan dinyatakan tergolong valid, karena hasil pengujian setiap soal telah mencapai batas koefisien yang telah ditentukan. pengujian validitas dilakukan dikelas II sekolah dasar dengan jumlah sampel 25 orang peserta didik, hasilnya dapat dilihat pada tabel 2 berikut ini :

Tabel 2. Hasil analisis validitas butir-butir tes awal

\begin{tabular}{cccc}
\hline No & Rxy & r table & Keterangan \\
\hline 1 & 0,7670 & 0,396 & Valid \\
2 & 0,5198 & 0,396 & Valid \\
3 & 0,3972 & 0,396 & Valid \\
4 & 0,4557 & 0,396 & Valid \\
\hline
\end{tabular}

Soal-soal itu dapat katakan valid dalam penelitian ini, jika soal-soal tersebut mempunyai koefisien korelasi yang cukup besar berkisar 0,40- 1,00 perhitungan hasil analisis uji validitas (untuk 4 pokok uji) untuk soal nomor 1 diperoleh 0,7670 berarti soal dikatakan valid. Dari hasil validitas angket soal tes awal dapat dilihat bahwa dari jumlah keseluruhan pertanyaan sebanyak 4 pertanyaan maka dapat diketahui bahwa seluruh pertanyaan tersebut valid artinya dapat digunakan untuk penelitian selanjutnya.

Setelah dilakukan uji validitas, selanjutnya dihitung uji reliabilitas untuk mengetahui instrumen tersebut reliabel atau tidak [18-19]. Dari perhitungan yang dilakukan didapatkan hasil bahwa instrumen tersebut dinyatakan tergolong reliabel atau dapat dipercaya, maksudnya dapat dipercaya untuk digunakan sebagai alat pengumpul data, karena instrumen tersebut sudah baik [20-21], dan apabila datanya memang benar sesuai dengan kenyataan dan berapa kalipun diambil akan tetap sama. Setelah semua dilakukan, dilanjutkan dengan menghitung tingkat kesukaran, dan daya beda untuk mengetahui hasil penelitian yang telah dilakukan [22]. Untuk melihat taraf kesukaran soal dilihat pada tabel 3 dibawah ini:

Tabel 3. Taraf kesukaran soal

\begin{tabular}{ccc}
\hline No soal & TK & Klasifikasi \\
\hline 1 & 0,84 & Mudah \\
2 & 0,84 & Mudah \\
3 & 0,84 & Mudah \\
4 & 0,88 & Mudah \\
\hline
\end{tabular}

Berdasarkan perhitungan hasil analisis uji tingkat kesukaran pokok uji dalam rangka validitas (untuk 4 pokok uji) untuk soal nomor satu diperoleh: 0,84 berarti tingkat kesukaran Mudah karena berada diantara $0,70<\mathrm{P} \leq 1,00$. Untuk melihat daya pembeda soal maka dapat dilihat pada tabel 4 dibawah ini: 
Tabel 4. Daya Pembeda Soal

\begin{tabular}{ccccccccc}
\hline No soal & BA & BB & JA & PA & JB & PB & D & Klasifikasi \\
\hline 1 & 13 & 11 & 13 & 1,000 & 12 & 0,916 & 0,840 & Baik sekali \\
2 & 12 & 12 & 13 & 0,923 & 12 & 1,000 & 0,770 & Baik sekali \\
3 & 13 & 11 & 13 & 1,000 & 12 & 0,916 & 0,840 & Baik sekali \\
4 & 10 & 12 & 13 & 0,769 & 12 & 1,000 & 0,770 & Baik sekali \\
\hline
\end{tabular}

Berdasarkan perhitungan hasil analisis uji coba daya beda pokok uji dalam rangka validitas (untuk 4 pokok uji) untuk soal nomor 1 diperoleh 0,840 (Baik sekali) karena berada antara $0,70<\mathrm{D} \leq 1,00$ [23]. Jadi, selisih proporsi jawaban peserta didik setelah diukur rata-rata memiliki kriteria yang baik.

Setelah semua instrumen dianalisis dan di olah menggunakan beberapa pengujian dan akhirnya dinyatakan valid, selanjutnya dilakukan pretest terhadap kelas kontrol dan kelas eksperimen dengan menggunakan instrumen soal yang telah diuji kevalidannya [24]. Hasilnya memiliki kemampuan yang hampir sama terhadap materi yang diajarkan. Jumlah siswa masing-masing subjek penelitian yaitu kelas II C berjumlah 23 orang peserta didik dan kelas II D berjumlah 25 orang peserta didik, dan semua peserta didik pada kelas tersebut mengikuti pretest dan postest yang diberikan. Pretest dilaksanakan diawal penelitian dilakukan, sedangkan postest dilaksanakan diakhir penelitian. Setelah dilakukan analisis data, maka didapatkan beberapa hasil penelitian berupa angka yang terdapat perbedaan rataa-rata belajar peserta didik kelas II Sekolah Dasar di Muara Bulian. Berikut adalah gambaran rata-rata jawaban peserta didik pada pretest, postest dan simpangan baku pada tabel 5:

Tabel 5. Rata-rata hasil belajar peseta didik, pretest, postest, dan simpangan baku

\begin{tabular}{|c|c|c|c|}
\hline Kelas & Jumlah siswa & Rata-rata & Simpangan Baku \\
\hline \multicolumn{4}{|c|}{ PRETEST } \\
\hline Kelas kontrol (II C) & 23 & 57,84 & 18,03 \\
\hline Kelas eksperimen (II D) & 25 & 51,62 & 22,03 \\
\hline \multicolumn{4}{|c|}{ POSTEST } \\
\hline Kelas kontrol (II C) & 23 & 62,86 & 16,40 \\
\hline Kelas eksperimen (II D) & 25 & 88,2 & 14,45 \\
\hline
\end{tabular}

Hasil pretest kelas kontrol diperoleh rata-rata yaitu 57,84 dengan simpangan baku (S) yaitu 18,03 dan variansi $\left(\mathrm{S}^{2}\right)$ yaitu 325,16 . Sedangkan hasil pretest kelas eksperimen diperoleh rata-rata yaitu 51,62 dengan simpangan baku (S) yaitu 22,03 dan variansi $\left(\mathrm{S}^{2}\right)$ yaitu 485,67. Setelah hasil pretest, selanjutnya hasil dari postest dari kelas eksperimen dengan menggunakan metode drill diperoleh rata-rata yaitu 88,2 dengan simpangan baku (S) yaitu 14,45 dan variansi $\left(\mathrm{S}^{2}\right)$ yaitu 209. Sedangkan kelas kontrol yang diajarkan tanpa menggunakan metode drill diperoleh rata-rata yaitu 62,86 dengan simpangan baku (S) yaitu 16,40 dan variansi $\left(S^{2}\right)$ yaitu 173,72 .

Penelitian ini dilaksanakan di dua kelas yang terdiri dari kelas II C sebagai kelas kontrol dan kelas II D sebagai kelas eksperimen. Sebelum menguji hipotesis dengan uji t, dilakukan terlebih dahulu uji normalitas dan uji homogenitas. Uji normalitas dilakukan dengan menggunakan uji liliefors. Uji normalitas dilakukan untuk mengetahui apakah data yang diperoleh peserta didik berdistribusi normal atau tidak, baik data tes awal maupun tes akhir [25]. Uji normalitas dilakukan dengan menggunakan uji liliefors. Uji normalitas dilakukan untuk mengetahui apakah data yang diperoleh peserta didik berdistribusi normal atau tidak, baik data tes awal maupun tes akhir. Dari hasil perhitungan didapat harga $\mathrm{L}_{\text {hitung }}$ dan $\mathrm{L}_{\text {tabel }}$ pada taraf 0,5 seperti tercantum pada taber 6:

Tabel 6. Hasil Analisis Uji Normalitas Kelompok Sampel

\begin{tabular}{lcccc}
\hline \multicolumn{1}{c}{ Kelas } & Jumlah peserta didik & $\mathbf{L}_{\text {hitumg }}$ & $\mathbf{L}_{\text {tabel }}$ & Keterangan \\
\hline Kelas kontrol & 23 & 0,227 & 0,231 & $\mathrm{~L}_{\text {hitung }}<\mathrm{L}_{\text {tabel }}$ \\
Kelas eksperimen & 25 & 0,221 & 0,231 & $\mathrm{~L}_{\text {hitung }}<\mathrm{L}_{\text {tabel }}$ \\
\hline
\end{tabular}

Berdasarkan tabel 4 diatas terlihat perbandingan harga $\mathrm{L}_{\text {hitung }}<\mathrm{L}_{\text {tabel }}$. Pada taraf 0,05 ini berarti data hasil jawaban peserta didik baik pada kelas kontrol maupun kelas eksperimen berdistribusi normal. 
Uji homogenitas dilakukan ketika selesai menghitung hasil data postest dari kelas eksperimen maupun kelas kontrol. Adapun data yang harus dihitung yaitu seperti, variansi, simpangan baku, dan ratarata. Apabila semua perhitungan tersebut telah dilakukan maka baru bisa menghitung uji homogenitas, karena untuk melakukan uji homogenitas dibutuhkan simpangan baku, jumlah siswa, dan variansi.Uji homogenitas variansi dilakukan dengan menggunakan uji F. Uji homogenitas dilakukan untuk mengetahui apakah data awal dan data akhir memiliki varians yang sama atau tidak. Dari hasil perhitungan didapat harga $\mathrm{F}_{\text {hitung }}$ dan $\mathrm{F}_{\text {tabel }}$ seperti tercantum pada tabel 7:

Tabel 7. Hasil analisis uji homogenitas kelompok sampel

\begin{tabular}{ccc}
\hline $\mathrm{F}_{\text {hitung }}$ & $\mathrm{F}_{\text {tabel }}$ & Keterangan \\
\hline 1,20 & 3,20 & $\mathrm{~F}_{\text {hitung }}<\mathrm{F}_{\text {tabel }}$ \\
\hline
\end{tabular}

Dari hasil analisi uji homogenitas variansi uji $\mathrm{F}$ terlihat $\mathrm{F}_{\text {hitung }}=$ dan $\mathrm{F}_{\text {tabel }}$. Karena $\mathrm{F}_{\text {hitung }}<\mathrm{F}_{\text {tabel }}$ maka dapat dinyatakan bahwa kedua kelompok memiliki variansi yang homogen pada $\alpha=0,5$. Setelah uji homogenitas dilakukan, pengujian tersebut mendapatkan hasil bahwa keduanya mempunyai variansi yang homogen.

Untuk melihat pengaruh metode Drill terhadap kemampuan menggali informasi dari dongeng, maka dilakukan uji hipotesis. Uji hipotesis dilakukan untuk mengetahui apakah terdapat perbedaan hasil jawaban siswa pada kelas kontrol dan kelas eksperimen berdasarkan perhitungan uji t diperoleh seperti yang tercantum di tabel 8:

Tabel 8. Hasil uji hipotesis

\begin{tabular}{ccc}
\hline $\mathbf{T}_{\text {hitung }}$ & $\mathbf{T}_{\text {tabel }}$ & Keterangan \\
\hline 0,1362 & 2,01290 & $\mathrm{t}_{\text {hitung }}>\mathrm{t}_{\text {tabel }}$ \\
\hline
\end{tabular}

Dari uji hipotesis uji $\mathrm{t}$ diatas didapat $\mathrm{t}_{\text {hitung }}=0,1362$ dan $\mathrm{t}_{\mathrm{tabel}}=2,01290$ dengan $\mathrm{dk}=46$. Kriteria pengujian terima. Kriteria pengujian terima $\mathrm{H}_{\mathrm{o}}$ jika $\mathrm{t}_{\text {hitung }}<\mathrm{t}_{\text {tabel }}$, untuk harga-harga lain $\mathrm{H}_{\mathrm{o}}$ ditolak. Karena $t_{\text {hitung }}<t_{\text {tabel }}(0,1362<2,01290)$ berarti $\mathrm{H}_{\mathrm{o}}$ ditolak dan $\mathrm{H}_{\mathrm{a}}$ diterima. Jadi , Penggunaan metode drill berpengaruh signifikan terhadap penguasaan kompetensi kemampuan menggali informasi dari dongeng (Fabel) peserta didik kelas II Sekolah Dasar.

Berdasarkan hasil penelitian yang dilakukan, diperoleh rata-rata hasil jawaban peserta didik pada kelas kontrol yaitu 54,2 dengan simpangan baku 16,40 berbeda dengan hasil jawaban peserta didik pada kelas eksperimen didapat rata-rata 88,4 dengan simpangan baku 14,45. Dari uji hipotesis uji t di atas diketahui bahwa penggunaan metode drill berpengaruh signifikan terhadap penguasaan kompetensi kemampuan menggali informasi dari dongeng (Fabel) peserta didik kelas II Sekolah Dasar.

Untuk memperoleh hasil yang maksimal diperlukan usaha yang tidak mudah. Melainkan harus melewati proses hingga memperoleh hasil yang baik sesuai dengan tujuan yang diinginkan.begitu juga dengan mengajar, diperlukan inovasi yang menarik dan kreatif hingga pembelajaran tersampaikan dengan baik dan bisa di pahami oleh peserta didik. Salah satu cara yang bisa dilakukan adalah pemilihan metode dalam mengajar. Pemilihan metode yang tepat akan menambah semangat belajar bagi peserta didik jika metode pembelajaran yang digunakan bervariasi tidak hanya ceramah. Ref [7] mengatakan bahwa "metode merupakan rencana keseluruhan bagi penyajian bahan bahasa secara rapi dan tertib, yang tidak ada bagianbagiannya yang berkontradiksi dan kesemuanya itu didasarkan pada pendekatan terpilih". Metode adalah cara yang digunakan untuk mengimplementasikan rencana yang sudah disusun dalam dalam kegiatan nyata agar tujuan yang telah disusun tercapai secara optimal. Artinya, metode digunakan untuk merealisasikan strategi yang telah diterapkan dalam proses pembelajaran.

\section{KESIMPULAN}

Berdasarkan hasil uji hipotesis terdapat perbedaan yang signifikan antara kemampuan menggali informasi dari dongeng yang menggunakan metode drill di kelas II sekolah dasar dengan kemampuan menggali informasi tanpa menggunakan metode drill.

\section{UCAPAN TERIMA KASIH}

Peneliti mengucapkan terima kasih kepada kepala sekolah dan guru serta siswa yang telah memberikan izin kepada para peneliti untuk melakukan penelitian ini. 


\section{REFERENSI}

[1] P. Anjayani, and S. Suprapto. "Error analysis on the use of prepositions in students' writing (a case study of the eleventh grade students of SMA negeri 9 semarang in the academic year of 2014/2015)," ELT Forum: Journal of English Language Teaching, vol. 5 no. 2), 2016.

[2] E. Suriyanti. "Hubungan Minat Baca dan Penguasaan Kosakata dengan Pemahaman Membaca Siswa Kelas VII SMP Islam Banda Aceh," Master Bahasa, vol. 5 no. 2, pp.128-136, 2017.

[3] D. Patiung. "Membaca Sebagai Sumber Pengembangan Intelektual," Al Daulah: Jurnal Hukum Pidana dan Ketatanegaraan, vol. 5 no. 2, pp. 352-376, 2016.

[4] Permendikbud. "Peraturan Menteri Pendidikan dan Kebudayaan Nomor 24 Tahun 2016 Tentang Kompetensi Inti Dan Kompetensi Dasar Pelajaran Pada Pendidikan Dasar Dan Menengah,” 2016.

[5] L. R. Wachidah, H. Suwignyo, and N. Widiati. "Potensi Karakter Tokoh dalam Cerita Rakyat sebagai Bahan Bacaan Literasi Moral," Jurnal Pendidikan: Teori, Penelitian, dan Pengembangan, vol. 2 no. 7, pp. 894-901, 2017.

[6] Y. Kiliç. "Survey on effects of fairy tales on Turkish language training from secondary school students perspective," Educational Research and Reviews, vol. 10 no. 4, pp. 388-396, 2015.

[7] Y. Abidin. "Pembelajaran Bahasa Berbasis Pendidikan Karakter," PT Refika Aditama, 2015.

[8] N. Wahyuni. "Penggunaan Metode Drill Dalam Pembelajaran Matematika," Online, vol. 2 no. 1, pp. 399-896, 2013.

[9] Sugiyono. “Metode Penelitian Pendidikan (Pendekatan Kuantitatif, Kulitatif, dan R\&D),” Alfabeta, 2016.

[10] K. Uno. “Assessment Pembelajaran," PT Bumi Aksara, 2013.

[11] A. Astalini, D. Darmaji, D. A. Kurniawan, and A. Destianti. "Description of the Dimensions Attitudes towards Science in Junior High School at Muaro Jambi,” IJSBAR, vol. 47 no. 1, pp. 1-11, 2019.

[12] Syahrial, Asrial, D. A. Kurniawan, R. A. Pratama, and R. Perdana. "Towards Improving The Critical Thinking Skills of Pre-service Teachers in Indonesia," Journal of Education and Learning (EduLearn), vol. 13 no. 4, pp. 575-582, 2018.

[13] Astalini, Darmaji, L. R. Sholihah, and R. Perdana. "Characteristics of Students Attitude to Physics in Muaro Jambi High School," Humanities and Social Sciences Reviews (HSSR), vol. 7 no. 2, pp. 91-99, 2019.

[14] D. Darmaji, D. A. Kurniawan, A. Astalini, A. Lumbantoruan, and S. C. Samosir. " Mobile Learning in Higher Education for The Industrial Revolution 4.0: Perception and Response of Physics Practicum,” International Journal of Interactive Mobile Technologies (iJIM), vol. 13 no. 9, pp. 4-20, 2019.

[15] Astalini, Darmaji, H. Pathoni, W. Kurniawan, Jufrida, D. A. Kurniawan, and R. Perdana. "Motivation and Attitude of Students on Physics Subject in the Middle School in Indonesia," International Education Studies (IES) Journal, vol. 12 no. 9, pp. 15-26, 2019.

[16] D. Darmaji, A. Astalini, D. A. Kurniawan, and R. Perdana. "A Study Relationship Attitude Toward Physics, Motivation, and Character Discipline Students Senior High School in Indonesia," International Journal of Learning and Teaching, vol. 11 no. 3, pp. 99-109, 2019.

[17] D. A. Kurniawan, Darmaji, Astalini, and P. Sefiah. "Description of Science Process Skills for Physics Teacher's Candidate,” Azerbaijan Journal of Educational Studies, vol. 684 no. 3, pp. 71-85, 2018.

[18] Asrial, et al. "Identification: The Effect of Mathematical Competence on Pedagogic Competency of Prospective Teacher," Humanities and Social Sciences Reviews (HSSR), vol. 7 no. 4, pp. 85-92, 2019.

[19] Astalini, D. A. Kurniawan, Darmaji, A. D. Putri, and R. Nawangsih. "Identify Student's Attitude Towards the Subject of Natural Science,” Journal of Education and Learning (EduLearn), vol. 13 no. 3, pp. 386-394, 2019.

[20] Syahrial, et al. "Increased Behavior of Students' Attitudes to Cultural Values Using the Inquiry Learning Model Assisted by Ethnocontructivism," Journal of Educational Science and Technology, vol. 5 no. 2, pp. 176-188, 2019.

[21] Maison, Darmaji, Astalini, D. A. Kurniawan, and P. S. Indrawati. "Science Process Skills and Motivation," Humanities and Social Sciences Reviews (HSSR), vol. 7 no. 5, pp. 48-56, 2019.

[22] Asrial, Syahrial, D. A. Kurniawan, N. Amalina, and M. Subandiyo. "Description of Elementary Teacher Education Program's Student: Mapping Indonesian Language Competence for Prospective Teacher," The Educational Reviews, vol. 3 no. 2, pp. 21-27, 2019.

[23] D. A. Kurniawan, Astalini, Darmaji, and R. Melsayanti. "Students' Attitude Towards Natural Sciences," International Journal of Evaluation and Research in Education (IJERE), vol. 8 no. 3, pp. 463-468, 2019.

[24] Syahrial, Asrial, D. A. Kurniawan, and S. O. Piyana. "E-Modul Etnokontruktivisme: Implementasi pada Kelas V Sekolah Dasar Ditinjau Dari Persepsi, Minat dan Motivasi,” Jurnal Teknologi Pendidikan, vol. 21 no. 2, pp. 165$177,2019$.

[25] Jufrida, W. Kurniawan, Astalini, Darmaji, D. A. Kurniawan, and W. A. Maya. "Students' Attitude and Motivation in Mathematical Physics," International Journal of Evaluation and Research in Education (IJERE), vol. 8 no. 3 , pp. 401-408, 2019.

JBER. Vol. 1, No. 1, Januari 2020: 1 - 6 